\title{
GREEN SYNTHESIS AND CHARACTERIZATION OF MARINE YEAST-MEDIATED SILVER AND ZINC OXIDE NANOPARTICLES AND ASSESSMENT OF THEIR ANTIOXIDANT ACTIVITY
}

\author{
ASWATHY R, GABYLIS B, ANWESHA S, BHASKARA RAO KV* \\ Department of Biomedical Sciences, Molecular and Microbiology Laboratory, School of Biosciences and Technology, VIT University, \\ Vellore, Tamil Nadu, India. Email: kvbhaskararao@vit.ac.in
}

Received: 15 May 2017, Revised and Accepted: 29 June 2017

\section{ABSTRACT}

Objective: The present study focuses on the synthesis of silver and zinc oxide ( $\mathrm{ZnO}$ ) nanoparticles from marine yeasts, isolated from the sediments of the Bay of Bengal, Bakkhali coast, West Bengal, and India.

Methods: The marine sediment samples were diluted through serial diution and cultured onto yeast malt agar medium by the spread plate method. The selected yeast isolates were screened for the biosynthesis of silver and ZnO nanoparticles. Characterization of both the nanoparticles was done by applying ultraviolet (UV)-visible spectroscopy, atomic force microscopy, scanning electron microscopy, and Fourier transform infrared spectroscopy.

Results: A total of five marine yeasts isolates were able to synthesize silver and $\mathrm{ZnO}$ nanoparticles as evidence of the color change. Optical density was measured in UV-spectrometer at different time interval for the conformation of production of nanoparticles. The size of silver nanoparticle was $31.78 \mathrm{~nm}$ and $\mathrm{ZnO}$ nanoparticle was $86.27 \mathrm{~nm}$. The synthesized nanoparticles are then used for antioxidant assays.

Conclusions: We are concluding that marine yeast isolates SAG1 and SAG2 both are potential marine yeast isolates which can synthesize both the silver and ZnO nanoparticles. They also showed good antioxidant activity.

Keywords: Marine yeast, Silver nanoparticle, Zinc oxide nanoparticle, Scanning electron microscopy, Ultraviolet-spectophotometry, Fourier transform infra-red, Atomic force microscopy.

(c) 2017 The Authors. Published by Innovare Academic Sciences Pvt Ltd. This is an open access article under the CC BY license (http://creativecommons. org/licenses/by/4. 0/) DOI: http://dx.doi.org/10.22159/ajpcr.2017.v10i10.19979

\section{INTRODUCTION}

Nanotechnology is an innovative field which acts on all aspects of human's life [1,2]. Nanoscience is applicable for the industrial and commercial objectives, which is referred as nanotechnology [3]. A nanoparticle is a very small particle with a size of approximately $100 \mathrm{~nm}$. Inorganic nanoparticles contain magnetic nanoparticle, the noble metal nanoparticle such as silver and gold, also zinc oxide ( $\mathrm{ZnO})$ and titanium oxide which are semiconductor nanoparticles [4]. Recent studies have shown that nanoparticle from some materials such as metal oxides are capable of inducing eukaryotic cell death and in prokaryotic, cell growth is inhibited by its cytotoxic effect [5].

Nanoparticles can be synthesized by different methods involving physical methods, chemical methods, and biological methods [6]. In recent years, the demand to develop eco-friendly procedures with low cost and non-toxic methods for nanoparticle synthesis is increased [7,8]. There are reports of using different groups of microorganisms such as yeast, bacteria, fungi, and actinomycetes for the synthesis of nanoparticles. A few examples include, Aspergillus fumigatus (Ag nanoparticle), Pseudomonas aeruginosa (Au nanoparticle), Candida glabrata (cadmium nanoparticle), and Fusarium oxysporum (silver, gold, and zirconia nanoparticles) [9-12]. Nanoparticles synthesized biologically are multifunctional with diverse applications in biomedical field such as in therapeutics [13], tissue regeneration [14], drug delivery systems [15], separation techniques [16], and cancer therapy.

Nanoparticles, obtained from silver have unique electrical, thermal, and optical properties. In addition, silver nanoparticles are used for antimicrobial coatings, wound dressings, keyboards, and many textiles. Biomedical devices now are having silver nanoparticles in them, which can release a very low level of silver ions in a continuous action to provide protection against bacteria. $\mathrm{ZnO}$ is having several applications in gas sensing, optical, magnetic, and piezoelectric methods. Moreover, $\mathrm{ZnO}$ nanoparticles have strong adsorption ability, high catalytic efficiency, and they are also used for sunscreens production [17], rubber processing, as a fungicide, and in waste water treatment $[18,19]$. $\mathrm{ZnO}$ usage on the environment can overtake nano-titanium dioxide in the near future because it absorbs both ultraviolet (UV)-A and UV-B radiation, whereas, $\mathrm{TiO}_{2}$ can block UV-B only, and thereby giving better protection to the environment. $\mathrm{ZnO}$ has antimicrobial activities. It is capable of interacting with the cell surface of bacteria or with bacterial core and generates different bactericidal mechanisms [20]. It is recognized that among eukaryotes, yeast have the potential for synthesis nanoparticles.

Yeasts, single-celled eukaryotic organisms, are a type of fungi regarded as the "model organism" [20,21]. The major sources of yeast include fruits, grains, plants, and carbohydrate containing foods. Although some yeasts cause disease and spoilage in the foods, they are considered very important in the food industry [22].

There are reports on production of various bioactive compounds or secondary metabolites such as glucans, vitamins, killer toxins, and glutathione from yeasts. They are also having a variety of applications in food, pharmaceutical industries, cosmetic industries, and chemical industries and they also play a great role in environmental protection. They are used in brewing of alcohol, alcohol distillation, baking industries, and carbon dioxide production. Yeasts are having some other applications, namely, single-cell protein production, biofuel production, nanoparticles, fatty acids, pigment production, and also production of enzymes such as amylase, protease, lipases, and inulinases [23]. 
Marine yeasts can survive in sea water for a longer time than in fresh water. They have unique features in producing enzymes compared to terrestrial yeasts. Some examples of marine yeast genera are Candida, Clavispora, Mrakia, Cryptococcus, and Saccharomyces sp. [24]. There are reports of production of silver nanoparticles from marine yeast such as Candida sp. and Yarrowia sp. [25,26].

The purpose of the current study is to synthesize silver and $\mathrm{ZnO}$ nanoparticles from isolated marine yeasts from marine sediment samples.

\section{METHODS}

\section{Sample collection}

The marine sediment sample was collected from Bay of Bengal, Bakkhali Coast, West Bengal, India in January, 2016. It was then brought in sterile condition and stored in molecular biology and microbiology laboratory, VIT University, Vellore, at $4^{\circ} \mathrm{C}$ for further use.

\section{Isolation of marine yeast}

Isolation of marine yeast was done using serial dilution and spread plate technique. Yeast malt agar medium was prepared by the addition of $50 \%$ marine water and $50 \%$ distilled water for the cultivation of yeast isolates. The inoculated plates were incubated at room temperature $\left(30^{\circ} \mathrm{C}\right)$ for $2-3$ days. Pure cultures from the master plates were selected and streaked on to fresh plates under aseptic conditions.

\section{Identification of potential yeast strain}

Identification and characterization of the yeast isolates were done through colony morphology, Gram staining, scanning electron microscopy (SEM), and biochemical tests, namely, methyl red, Voges-Proskauer test, indole test, citrate utilization test, urease and carbohydrate utilization tests.

\section{Fermentation process}

Yeast cells were inoculated into production medium (containing glucose, yeast extract, maltose, and peptone) and incubated in shaking condition at $30^{\circ} \mathrm{C}$ for 3 days.

\section{Biosynthesis of silver and ZnO nanoparticles}

The cultured broth was collected after incubation and centrifuged at 8,000 rpm for 15 minutes. The supernatant was then used for the synthesis of silver and $\mathrm{ZnO}$ nanoparticles. In each $250 \mathrm{ml}$ Erlenmeyer conical flasks, $100 \mathrm{ml}$ of the supernatant from each culture was added and in that $1 \mathrm{~mm}$ of silver nitrate $\left(\mathrm{AgNO}_{3}\right)$ and ZnO was added separately. The inoculated conical flasks were incubated in a rotary incubator shaker at room temperature for 3-4 days $[27,28]$.

\section{Characterization of the $\mathrm{ZnO}$ and $\mathrm{AgNO}_{3}$ nanoparticles}

After the biosynthesis of silver and zinc nanoparticle, a portion of the broth was subjected to UV spectrophotometric analysis in different wavelengths and in specific time intervals. Atomic force microscopy (AFM) analysis was done to determine the shape and size of the silver and $\mathrm{ZnO}$ nanoparticles. Fourier transform infrared (FTIR) spectroscopy is carried for determining the functional groups which are present on the surface of the microbial cell that could be an important factor for the synthesis of silver and $\mathrm{ZnO}$ nanoparticles. SEM is done for getting the two-dimensional image.

\section{Antioxidant test}

\section{2,2-Diphenyl-1-picrylhydrazyl (DPPH) radical scavenging} activity

Standards of the samples were prepared with $20,40,60,80$, and 100 concentrations and to each of those standards, $1 \mathrm{ml}$ DPPH was added. Absorbance of those given standards was measured at $570 \mathrm{~nm}$ in UV spectroscope. Ascorbic acid was prepared as the positive control, and on the other hand, negative control was then prepared by mixing properly
$2 \mathrm{ml}$ methanol and $1 \mathrm{ml} \mathrm{DPPH}$. Total $3 \mathrm{ml}$ of that mixed methanol with DPPH was used as blank [29].

Equation for calculating DPPH scavenging activity:

$\left(A_{0}-A_{1} / A_{0}\right) 100$

Where,

$\mathrm{A}_{0}=$ Absorbance of control and $\mathrm{A}_{1}=$ Absorbance of sample

\section{RESULTS AND DISCUSSION}

Isolation of marine yeast

A total of 20 yeast isolates were recovered from the marine sediment samples. Morphologically distinct colonoies were selected for the futher studies.

\section{Screening for the synthesis of silver and ZnO nanoparticles} Among the 20 isolates screened for the synthesis of both the nanoparticles, only five isolates showed a color change (Figs. 1 and 2) after the addition of $\mathrm{AgNO}_{3}$ and $\mathrm{ZnO}$. These five isolates were named as SAG1, SAG2, SAG3, SAG4, and SAG5. SEM images of the potential two isolates are shown in Figs. 3 and 4.

\section{Characterization of yeast isolates}

Some biochemical tests such as methyl red, Voges-Proskauer, citrate utilization test, and indole tests were done. SAG1 and SAG4 showed positive results here. SAG2 and SAG3 isolates showed negative results for indole and MR, and the SAG5 strain showed negative results for VP. All the isolates were positive for urease production. Carbohydrate utilization tests were done using glucose and galactose. All the isolates showed positive results for this test (Table 1).

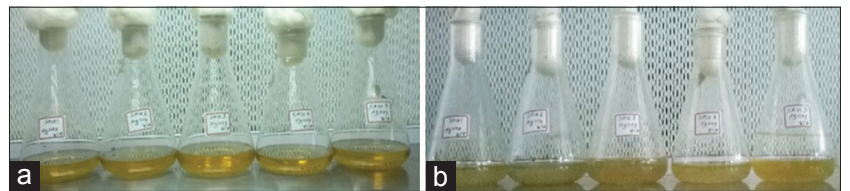

Fig. 1: Before (a) and after (b) the addition of silver nitrate

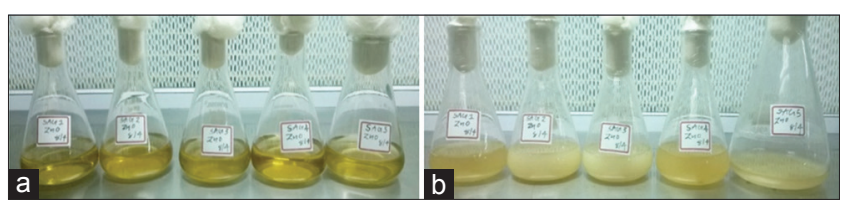

Fig. 2: Before (a) and after (b) the addition of zinc oxide

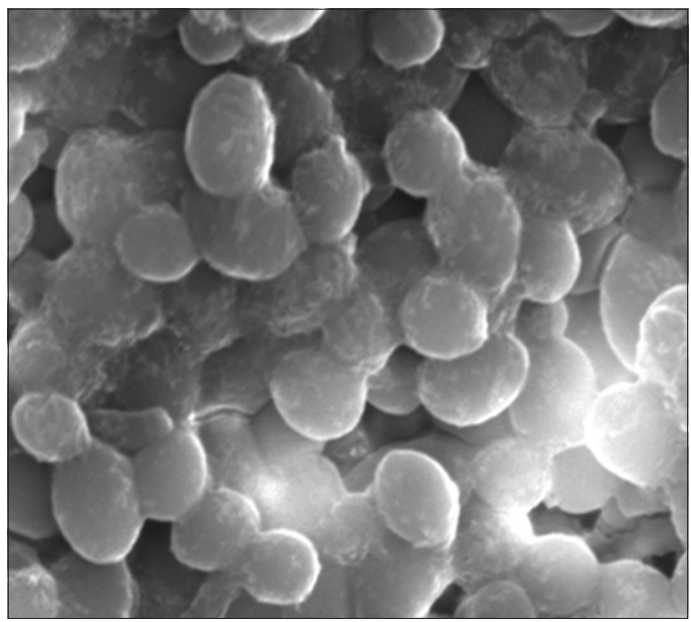

Fig. 3: Scanning electron microscopy image of SAG1 
Characterization of silver and $\mathrm{ZnO}$ nanoparticles

$U V$-spectrometer analysis of silver and $\mathrm{ZnO}$ nanoparticles

Among the five isolates, only two isolates (SAG1 and SAG2) showed a maximum absorbance for both the silver and $\mathrm{ZnO}$. Through twoway ANOVA analysis, both SAG 1 and SAG 2 showed a broad peak at 430-450 nm (Fig. 5) which confirmed the presence of silver nanoparticles, as surface plasmon resonance for silver nanoparticles generally occurs within that range only. The formation of the highest peak at approximately $330 \mathrm{~nm}$ (SAG1) and at $325 \mathrm{~nm}$ (SAG2) through the two-way ANOVA analysis is a confirmation of the presence of $\mathrm{ZnO}$

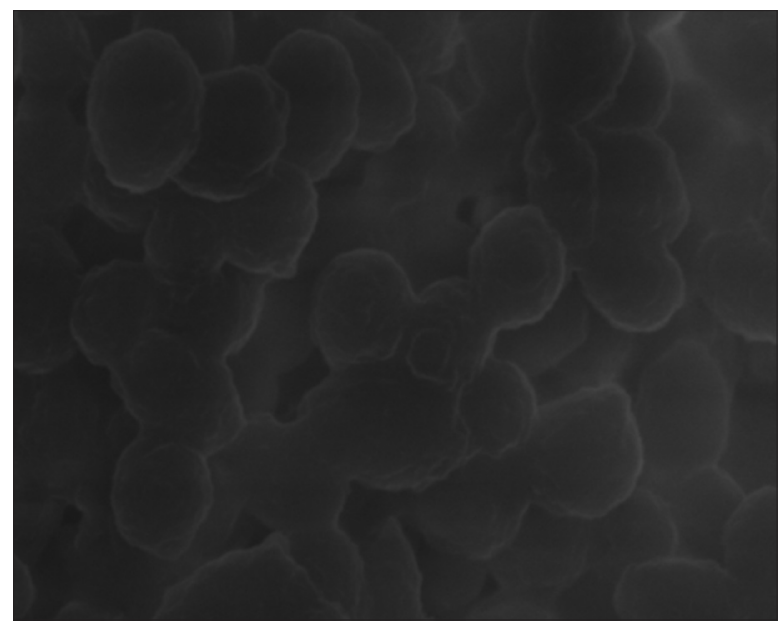

Fig. 4: Scanning electron microscopy image of SAG2

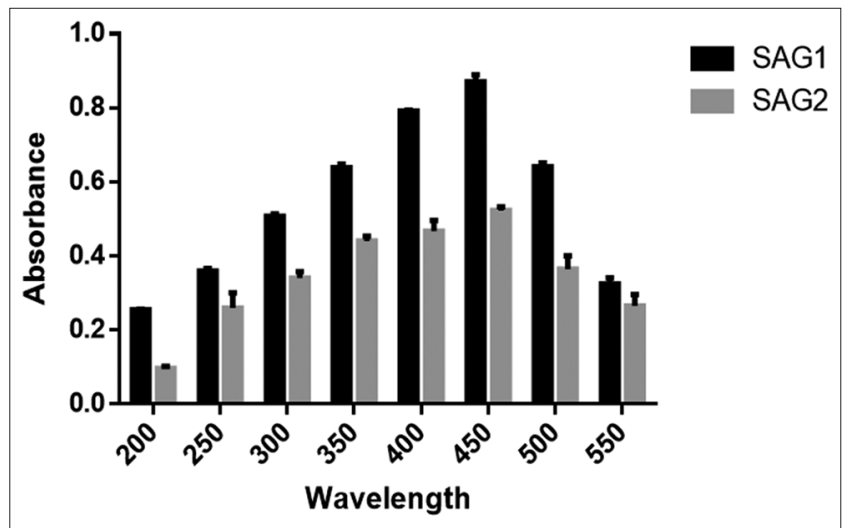

Fig. 5: Ultraviolet-visible spectrum of SAG1 and SAG2 for silver nanoparticles

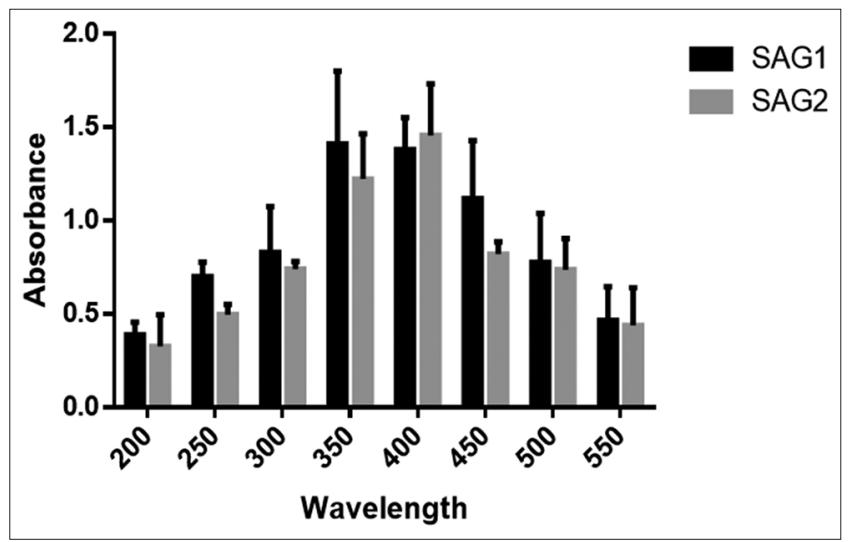

Fig. 6: Ultraviolet-visible spectrum of SAG1 and SAG2 for zinc oxide nanoparticles nanoparticles (Fig. 6). Absorbance was taken in UV-spectrometer in different time intervals with both the isolates in the particular wavelengths where they have shown higher activity in silver nanoparticles and $\mathrm{ZnO}$ nanoparticles production. Both the graphs showed an increase in absorbance in various time intervals $(0,6,12$, 18, 24, 30, 36, 42, and $48 \mathrm{hrs)} \mathrm{(Figs.} 7$ and 8). The color changed from yellow to dark brown with the increase of time period.

\section{AFM analysis for the nanoparticles}

To analyze the topographical structure of the synthesized AgNPs, AFM analysis was performed. Based on the results obtained in the UVspectroscopy, AFM analysis was carried out for both the nanoparticles synthesized by the isolate SAG1 only. From the AFM images, it can be

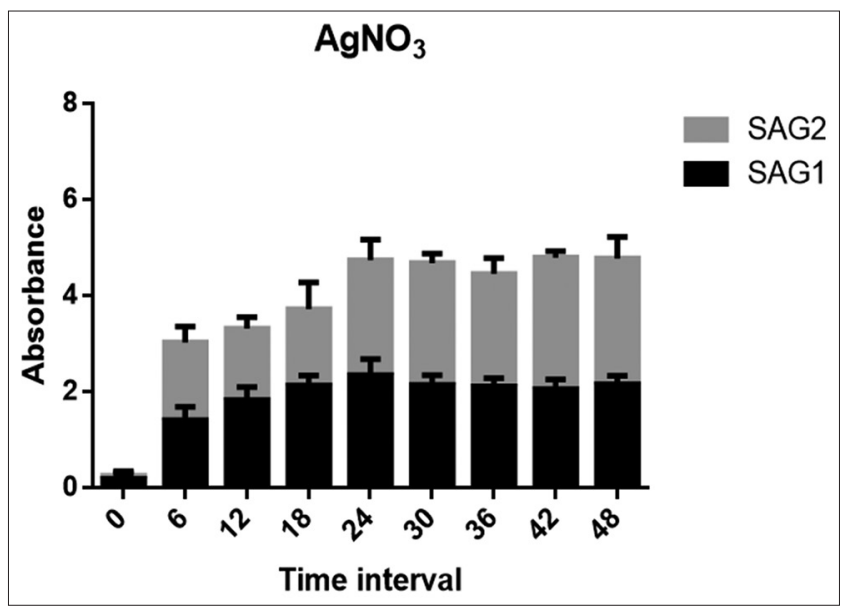

Fig. 7: Increase in absorbance in different time intervals of SAG1 and SAG2 for silver nanoparticles

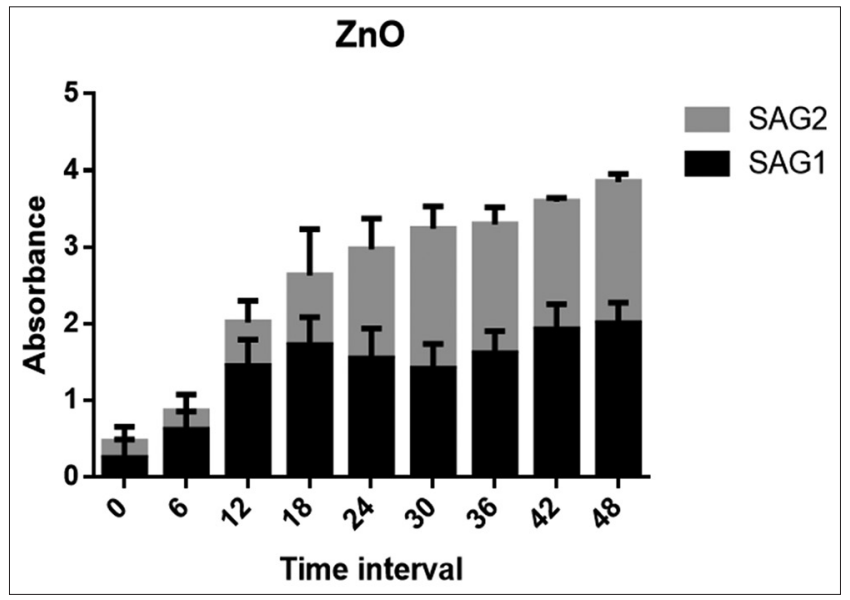

Fig. 8: Increase in absorbance in different time intervals of SAG1 and SAG2 for zinc oxide nanoparticles

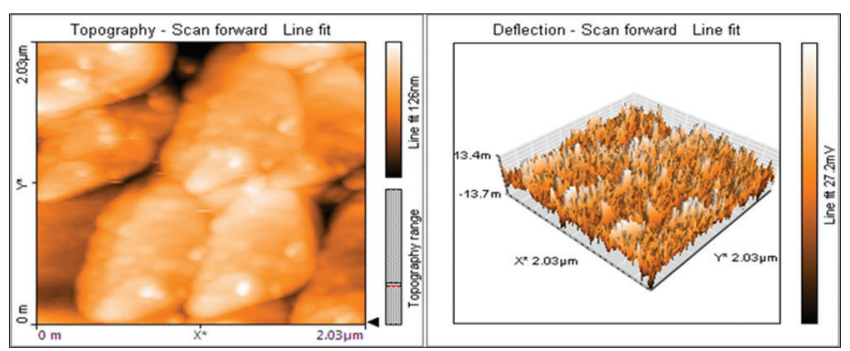

Fig. 9: Atomic force microscopy topography image of SAG1 silver nanoparticles 
Table 1: Biochemical characteristics of isolates

\begin{tabular}{llllllll}
\hline Isolates & Indole & MR & VP & Citrate & Urease & Glucose fermentation & Galactose fermentation \\
\hline SAG 1 & + & + & + & + & + & + & + \\
SAG 2 & - & - & + & + & + & + & + \\
SAG 3 & - & + & + & + & + & + & + \\
SAG 4 & + & + & - & + & + & + & + \\
SAG 5 & + & & + & & & + \\
\hline
\end{tabular}

Table 2: DPPH assay for analyzing antioxidant activity - AgNPs

\begin{tabular}{lll}
\hline Samples & Concentrations & \% of DPPH activity \\
\hline SAG1 & 100 & 63.63 \\
SAG2 & 80 & 65.12 \\
\hline
\end{tabular}

DPPH: 2,2-Diphenyl-1-picrylhydrazyl

Table 3: DPPH assay for analyzing antioxidant activity - ZnONPs

\begin{tabular}{lll}
\hline Samples & Concentrations & \% of DPPH activity \\
\hline SAG1 & 100 & 54.10 \\
SAG2 & 80 & 48.95 \\
\hline
\end{tabular}

DPPH: 2,2-Diphenyl-1-picrylhydrazyl

concluded that the shape of silver nanoparticle is round and size is approximately $31.78 \mathrm{~nm}$ (Fig. 9). On the other side, the shape of the $\mathrm{ZnO}$ nanoparticles is almost round and size is approximately $86.27 \mathrm{~nm}$ (Fig. 10).

\section{FTIR analysis of silver and ZnO nanoparticles}

The maximum peak for the synthesis of $\mathrm{ZnO}$ nanoparticles from the FTIR resulted in the range of $1300-1000 \mathrm{~cm}^{-1}$. The functional group C-0 is involved in the synthesis of this nanoparticle (Fig. 11). For $\mathrm{AgNO}_{3}$, maximum peak showed in the range of $3300-2500 \mathrm{~cm}^{-1}$ and the functional group involved here is $\mathrm{O}-\mathrm{H}$ (Fig. 12).

SEM analysis of the nanoparticles

The SEM images of the silver nanoparticles have been given as Figs. 13 and 14. The images revealed the uniformity in the size of the nanoparticles.

\section{DPPH assay for analyzing antioxidant activity}

DPPH is a biological free radical which is violet in color. The antioxidant ability of the sample can be expressed by their capacity to scavenge DPPH radical. On the basis of this scavenging property, free radicals will turn to yellow color by the antioxidants present in the sample. This change of color from violet to yellow indicates a positive test. SAG1 and SAG2 silver nanoparticles showed $63.63 \%$ and $65.12 \%$ scavenging activity (Table 2 ). On the other hand, SAG1 and SAG2 ZnO nanoparticles showed $54.10 \%$ and $48.95 \%$ scavenging activity (Table 3).

\section{DISCUSSION}

In the previous study, UV spectrophotometer analysis showed highest peak on the range of $400-450 \mathrm{~nm}$ which confirmed the presence of silver nanoparticles, and they also observed a broad peak in the range of 300-350 nm confirming the synthesis of ZnO nanoparticles which was quite similar to our study [30]. Similarly, in a recent study, they have checked the absorbance in increasing time intervals and got color change in the broth from yellow to dark brown after 24 hrs only [31]. However, in another study, they did not observe any color change after $72 \mathrm{hrs}$ also indicating there was no synthesis of silver nanoparticles [27]. We have got very similar AFM results for the characterization of the silver and $\mathrm{ZnO}$ nanoparticles observed in some previous studies, respectively [30,32]. We have got similar functional groups through FTIR analysis in some previous studies for the confirmation of AGNPs and ZnONPs,

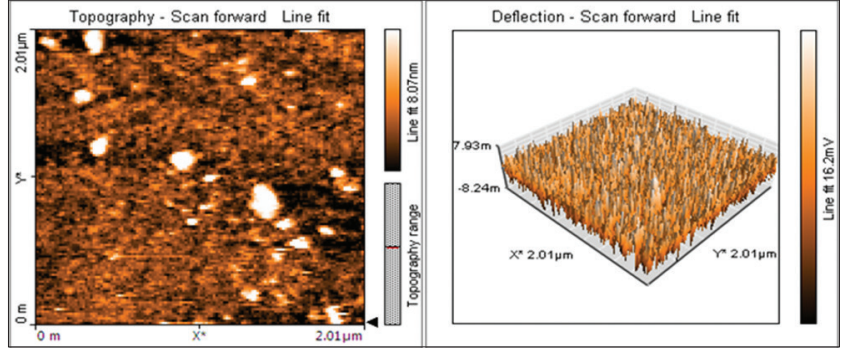

Fig. 10: Atomic force microscopy topography image of SAG1 zinc oxide nanoparticles

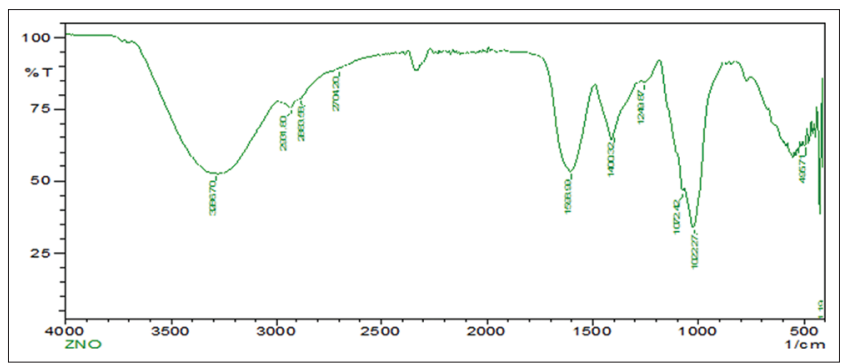

Fig. 11: Fourier transform infrared analysis of zinc oxide nanoparticles

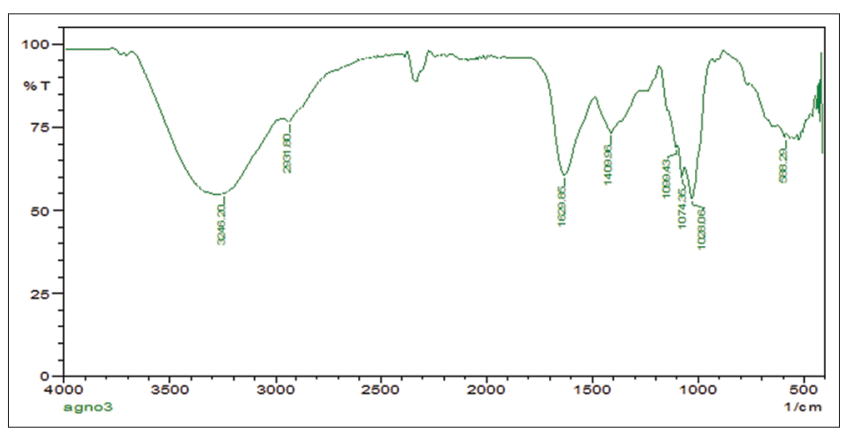

Fig. 12: Fourier transform infrared analysis of silver nanoparticles

respectively $[25,33]$. On the other hand, in a recent study, they have observed DPPH scavenging activity of synthesized silver nanoparticles extracted from leaf samples and they have found highest activity as $4.30 \mu \mathrm{g} / \mathrm{ml}$ [34]. Similarly, in Lingaraju et al. [35], synthesized $\mathrm{ZnO}$ nanoparticles showed good scavenging activity with inhibitory concentration $\left(\mathrm{IC}_{50}\right.$ ) value of $9.34 \mathrm{mg} / \mathrm{ml}$. In a recent study, they have also got the similar results [36]. In a similar study, methanolic extract of Lantana camara showed minimum IC C $_{50}$ value for DPPH assay $(48.75 \pm 2.34 \mu \mathrm{g} / \mathrm{ml})[37]$.

\section{CONCLUSION}

In this paper, green synthesis of silver nanoparticles and $\mathrm{ZnO}$ nanoparticles was done using marine yeast isolated from marine sediment sample of Bay of Bengal and West Bengal. Characterization and identification of both the nanoparticle were 


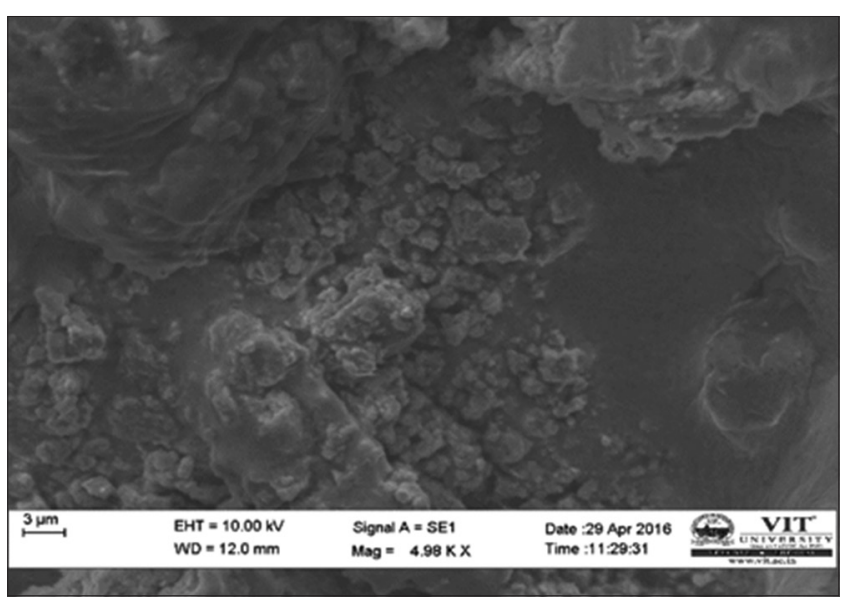

Fig. 13: Scanning electron microscopy image of silver nanoparticles

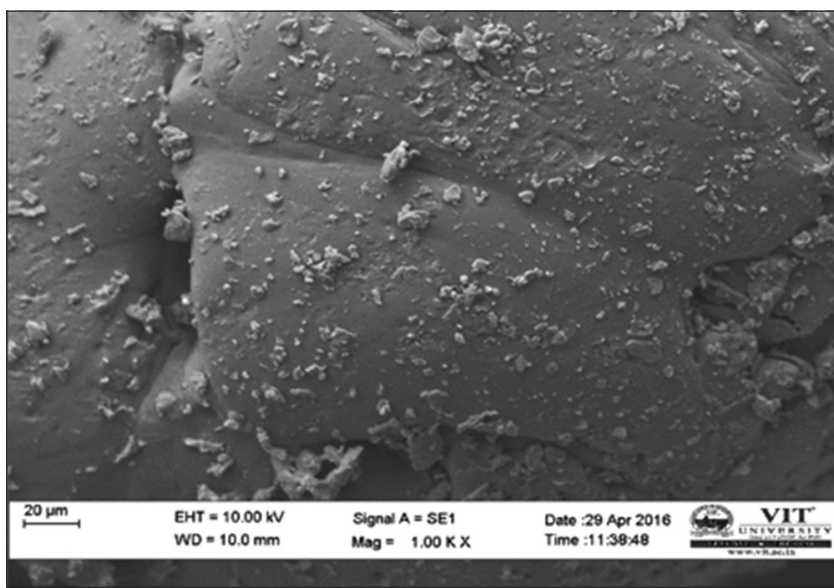

Fig. 14: Scanning electron microscopy image of zinc oxide nanoparticles

performed through UV-visible, SEM, and AFM. Antioxidant activity (DPPH) of the nanoparticles was also tested. We can conclude that marine yeast isolates SAG1 and SAG2 are very potential isolates and further work includes identification of these isolates using $18 \mathrm{~s}$ rRNA sequencing.

\section{ACKNOWLEDGMENT}

The authors are very much grateful to the management and all the staffs and technicians (SEM, FT-IR, and HPLC) of VIT University, Vellore, Tamil $\mathrm{Nadu}$, for their immense support to complete this study.

\section{REFERENCES}

1. Yadav SK, Mohanpuria P, Rana NK. Biosynthesis of nanoparticle: Technological concepts and future applications. J Nanopart Res 2008;10:507-17.

2. Liu J, Qiao SZ, Hu QH. Magnetic nanoparticles with mesoporous structures: Synthesis and applications. Magn Nanocom 2011;7:425-43.

3. Kim YC, Park NC, Shin JS, Lee SR, Lee YJ, Moon DJ. Partial oxidation of ethylene to ethylene oxide over nano sized $\mathrm{Ag} / \mathrm{Al} 2 \mathrm{o} 3$ catalysts. Catal Today 2003;87:153-62.

4. Anker JN, Hall WP, Lyandres O, Shah NC, Zhao J, Van Duyne RP. Biosensing with plasmonic nanosensors. Nat Mater 2008;7(6):442-53.

5. Silva GA. Neuroscience nanotechnology: Progress, opportunities and challenges. Nat Rev Neurosci 2006;7(1):65-74.

6. Ayyappan S, Srinivasa GR, Rao CN, Subbanna GN. Nanoparticles of $\mathrm{Ag}, \mathrm{Au}, \mathrm{Pd}$ and $\mathrm{Cu}$ produced by alcohol reduction of the salts. J Mater Res 1997;12:398-401

7. Chandran SP, Chaudhary M, Pasricha R, Ahmad A, Sastry M. Synthesis of gold nanotriangles and silver nanoparticles using Aloe vera plant extract. Biotechnol Prog 2006;22(2):577-83.

8. Ahmad A, Mukherjee P, Mandal D, Senapati S, Khan MI, Kumar R, et al. Enzyme mediated extracellular synthesis of CdS nanoparticles by the fungus, Fusarium oxysporum. J Am Chem Soc 2002;124(41):12108-9.

9. Ankamwar B, Chaudhary M, Murali S. Gold nano triangles biologically synthesized using tamarind leaf extract and potential application in vapour sensing. Synth React Inorg Met Org Chem 2005:35:19-26

10. Deneron CT, Reeser RN, Mehra RK, Carroll PJ, Kortan AR, Brus LE, et al. Biosynthesis of cadmium sulphide quantum semiconductor crystallites. Lett Nat 2006;338:596-7.

11. Mukherjee P, Senapati S, Mandal D, Ahmad A, Khan MI, Kumar R, et al. Extracellular synthesis of gold nanoparticles by the fungus Fusarium oxysporum. Chembiochem 2002;3(5):461-3.

12. Bansal V, Rautaray D, Bharde A, Ahire K, Sanyal A, Ahmad A, et al. Fungus mediated biosynthesis of silica and titania particles. J Mater Chem 2005;15:2583-9.

13. Kumar SA, Ayoobul AA, Absar A, Khan MI. Extracellular biosynthesis of CdSe quantum dots by the fungus Fusarium oxysporum. J Biomed Nanobiotechnol 2007;3:190-4.

14. Sriram MI, Kanth SB, Kalishwaralal K, Gurunathan S. Antitumor activity of silver nanoparticles in Dalton's lymphoma ascites tumor model. Int J Nanomedicine 2010;5:753-62.

15. Christina G, Vossen DL, Imhof A, Blaaderen AV. A general method to coat colloidal particles with silica. Langmuir 2003;19:6693-700.

16. Li WR, Xie XB, Shi QS, Zeng HY, Ou-Yang YS, Chen YB. Antibacterial activity and mechanism of silver nanoparticles on Escherichia coli. Appl Microbiol Biotechnol 2010;85(4):1115-22.

17. Wang X, Lu J, Xu M, Xing B. Sorption of pyrene by regular and nanoscaled metal oxide particles: Influence of adsorbed organic matter. Environ Sci Technol 2008;42(19):7267-72.

18. Seil JT, Webster TJ. Antimicrobial applications of nanotechnology: Methods and literature. Int J Nanomedicine 2012;7:2767-81.

19. Aitman TJ, Boone C, Churchill GA, Hengartner MO, Mackay TF, Stemple DL. The future of model organism in human disease research. Nat Rev Genet 2011;18:575-82.

20. Anusha SU, Sundar SK, Williams PG. Studies on the isolation and characterisation of marine yeast, $\beta$-glucan production and immune stimulatory activity on Carassiusm auratus. Int J Curr Microbiol Appl Sci 2014;3:230-40.

21. Fell JW. Collection and identification of marine yeasts. In: Paul J, editor. Methods in Microbiology. New York: Academic Press; 2001. p. 347-56.

22. Raj A, Baby G, Dutta S, Sarkar A, Rao KV. Isolation, characterization and antioxidant activity of lipase enzyme producing yeasts isolated from spoiled sweet sample. Der Pharm Lett 2016;8:129-35.

23. Zaky AS, Tucker GA, Daw ZY, Du C. Marine yeast isolation and industrial application. FEMS Yeast Res 2014;14(6):813-25.

24. Zhenming C, Zhiqiang L, Lingmei G, Fang G, Chunling M, Xianghong $\mathrm{W}$, et al. Marine yeasts and their applications in mariculture. J Ocean Univ China 2006;5:251-6.

25. Apte M, Sambre D, Gaikawad S, Joshi S, Bankar A, Kumar AR, et al. Psychrotrophic yeast Yarrowia lipolytica NCYC 789 mediates the synthesis of antimicrobial silver nanoparticles via cell-associated melanin. AMB Express 2013;3(1):32.

26. Kumar D, Karthik SL, Kumar G, Rao KV. Biosynthesis of silver nanoparticles from marine yeast and their antimicrobial activity against multidrug resistant pathogens. Pharma 2011;3:1100-11.

27. Waghmare SS, Deshmukh MA, Kulkarni SW, Oswaldo LA. Biosynthesis and characterization of manganese and zinc nanoparticles. Univ J Environ Res Technol 2011;1:64-9.

28. Subashini J, Kannabiran K. Antimicrobial activity of Streptomyces sp. VITBT7 and its synthesized silver nanoparticles against medically important fungal and bacterial pathogens. Der Pharm Lett 2013;5:192-200

29. Sarkar A, Abhyankar I, Saha P, Kumar SR, Rao KV. Antioxidant, haemolytic activity of L-glutaminase producing marine actinobacteria isolated from salt pan soil of coastal Andhra Pradesh. Res J Pharm Technol 2014;7:544-9.

30. Kumar S, Rao KV. Anti-dermatophytic and anti-cytotoxic activity of marine actinobacteria mediated biosynthesized silver nanoparticles. Res J Biotechnol 2014;9:58-65.

31. Logeshwari P, Silambarasan S, Abraham J. Synthesis of silver nanoparticles using plants extract and analysis of their antimicrobial property. J Saudi Chem Soc 2012;4:536-40. 
32. Talam S, Karumuri SR, Gunnam N. Synthesis, characterization, and spectroscopic properties of $\mathrm{ZnO}$ nanoparticles. ISRN Nanotechnol 2012;2012:1-6.

33. Baskar G, Chandhuru J, Fahad KS, Praveen AS. Mycological synthesis, characterization and antifungal activity of zinc oxide nanoparticles. Asian Pharm Online 2013;3:542-6.

34. Sundararajan B, Mahendran G, Thamaraiselvi R, Kumar BD. Biological activities of synthesized silver nanoparticles from Cardiospermum halicacabum L. Bull Matter Sci 2016;39:423-31.

35. Lingaraju K, Naika HR, Manjunath K, Basavaraj RB, Nagabhushana H,
Nagaraju G, et al. Biogenic synthesis of zinc oxide nanoparticles using Ruta graveolens (L.) and their antibacterial and antioxidant activities. Appl Nanosci 2016;6:703-10.

36. Hamed MM, Abdalla AM, Ahmed MG, Saleh SA. Chemical constituents, in vitro antioxidant activity, oral acute toxicity and $\mathrm{LD}_{50}$ determination Moringa oleifera leaves. Int $\mathrm{J}$ Pharm Pharm Sci 2017:9:240-7.

37. Badgujar N, Mistry K, Patel J. v. negundo, 1. camara and b. variegate plants leaf extract exhibit considerable in vitro antioxidant and anticancer activities. Int J Pharm Pharm Sci 2017;9:227-32. 